\title{
Prostatic Small Cell Carcinoma: Diagnosis and Management
}

\author{
Parminder Singh", Amit. M. Algotar, Erika R. Bracamonte \\ The University of Arizona Cancer Center, Tucson, USA. \\ Email: ${ }^{*}$ psingh@uacc.arizona.edu \\ Received February $28^{\text {th }}, 2013$; revised March 22 ${ }^{\text {nd }}, 2013$; accepted March $31^{\text {st }}, 2013$ \\ Copyright (C) 2013 Parminder Singh et al. This is an open access article distributed under the Creative Commons Attribution License, \\ which permits unrestricted use, distribution, and reproduction in any medium, provided the original work is properly cited.
}

\begin{abstract}
Prostatic small cell carcinoma (PSCC) is a distinct clinical phenotype of prostate cancer. Although rare, this phenotype is highly aggressive with very high mortality. Due to this, it is imperative for clinicians to be aware of it, diagnose it early and treat it appropriately. In this article we discuss the current literature, outline a plan for its diagnosis and management, and highlight latest research on this topic.
\end{abstract}

Keywords: Prostatic Small Cell Carcinoma; Prostate Cancer; Neuroendocrine Tumor

\section{Introduction}

Prostatic small cell carcinoma (PSCC) is a distinct and aggressive clinical phenotype of prostate cancer. The clinical entity is characterized by frequent non-osseous visceral metastasis, poor response to androgen ablation, serum prostate specific antigen (PSA) levels not correlating with response or disease progression and non-durable responses to cisplatin based chemotherapy. In this article we discuss the current literature, outline a plan for its diagnosis and management, and highlight latest research on this topic.

\section{Epidemiology}

Data from the surveillance, epidemiology and end results (SEER) program indicates that the incidence rate for PSCC is 0.35 cases per million per year [1]. The incidence is higher amongst African-American as compared to Caucasian men $(0.51$ vs $0.34, p=0.07)$. Out of the 502 PSCC cases identified in SEER 17, 87\% identified themselves as Caucasians, $8 \%$ as African-Americans, and remaining $5 \%$ as other or unknown races. Median age at diagnosis for PSCC was 73.1years, and median PSA at diagnosis was $10.9 \mathrm{ng} / \mathrm{ml}$. An interesting point to note is that $51.8 \%$ of patients diagnosed with PSCC presented with PSA $\leq 5 \mathrm{ng} / \mathrm{ml}$ and $51.5 \%$ of patients were staged to have distant metastasis at diagnosis. Both these numbers are higher than comparative numbers for any other prostate cancer subtype and indicate the aggressive nature of this variant. Five-year and median overall survival for

\footnotetext{
${ }^{*}$ Corresponding author.
}

PSCC are the lowest among prostate cancer subtypes at $12.6 \%$ and 10 months respectively. As compared to Caucasian patients, African-American patients demonstrate slightly higher survival $(16.1 \%$ vs $12.8 \%)$ [1]. These data combined with the incidence data imply that although African-American men are more likely to be diagnosed with PSCC, the disease is less aggressive in case as compared to their Caucasian counter parts. Pure PSCC is seen in $50 \%$ of cases and the rest demonstrate an admixture of PSCC and adenocarcinoma [2]. PSCC is rarely a primary presentation. More commonly it is observed to emerge as the disease becomes castrate resistant. Aparicio et al had observed features of small cell differentiation in $25 \%$ of patients with chemotherapy naïve hormone refractory prostate cancer [3]. Small cell carcinomas (SCC) of prostate or of any other organ of origin are often characterized with rapidly growing and highly metastatic disease [3].

Pure PSCC arising de novo with no or minimal adenocarcinoma component behaves more aggressively than mixed variety or adenocarcinoma showing cells with neuroendocrine differentiation. The later may also have higher PSA values than the pure type PSCC [4].

\section{Histopathology and Molecular Markers}

Prostatic small cell carcinoma (PSCC) demonstrates histologic features similar to small cell carcinomas arising in other organs. Most cases of PSCC show traditional "oat cell" morphology on routine histology, including scant cytoplasm, nuclear molding, finely dispersed nuclear chromatin, inconspicuous nucleoli and frequent 
apoptosis and mitotic activity, while approximately $1 / 3$ of cases may contain features of "intermediate" neuroendocrine carcinoma, with more abundant cytoplasm and occasional visible nucleoli (Figure 1). Occasional giant tumor cells with "smudgy" chromatin may be present [2]. PSCC may exist as a pure subtype, or in combination with traditional prostatic adenocarcinoma. When present in addition to conventional adenocarcinoma, the PSCC component may go unrecognized, i.e. interpreted as a "de-differentiated" or high grade (Gleason pattern 5) area [2]. The cytologic appearance of primary and metastatic PSCC on fine needle aspirate material is also similar to aspirates of SCC arising from the lung or other organs. Aspirates from PSCC are highly cellular, and contain a large proportion of single tumor cells. The neoplastic cells have minimal cytoplasm, with fine nuclear chromatin and variable mitoses. Numerous apoptotic bodies are seen. Cell clusters may demonstrate nuclear molding [5].

Several authors have investigated the immunohistochemical staining pattern of PSCC. The majority of tumors express at least one, and often several neuroendocrine markers, such as synaptophysin, CD56 or chromogranin [2,6] (Figure 2). In a study of 95 cases of PSCC, neuroendocrine markers were positive in $94 \%$ of tumors, and CD56 was found to be the most sensitive marker [2]. Approximately 50 to $80 \%$ of cases express thyroid transcription factor 1 (TTF-1), which cannot be used to distinguish PSCC from lung primary SCC $[2,6]$. While immunohistochemical markers of neuroendocrine differenttiation are usually detected, organ specific markers such as prostate specific antigen (PSA), prostatic acid phosphatase (PSAP), androgen receptor (AR), p501s (prostein) and p504s (AMACR) are often absent. Positive staining has been described in approximately $15 \%-20 \%$ of cases for PSA, $17 \%$ cases for AR, 25\% - 29\% cases for PSAP, $28 \%$ cases for $\mathrm{p} 501 \mathrm{~s}$, and $47 \%$ of cases for p501s $[2,6]$. When present, staining is often focal and weak compared to conventional prostatic adenocarcinoma. The absence of AR staining by immunohistochemistry reflects the clinical lack of response by PSCC to hormonal therapy. Most cases of PSCC show tumor positivity for p53 by immunohistochemistry, and genomic sequencing studies have confirmed the presence of p53 mutations, suggesting a role for the p53 pathway in tumor genesis [7]. Although positive immunohistochemical staining for c-Kit (CD117) and PDGFR have also been described in PSCC, no Kit or PDGFR mutations have been detected by PCR analysis [8]. Newer studies looking for new molecular targets have identified high levels of transcription factors characteristics of neural precursor cell such as ASCL1 [9], overexpression of MYCN proto-oncogene overexpression of MYCN proto-oncogene [10]. In addition to that they also observed Aurora Kinase A (AURKA). AURKA is involved in regulating the function of centrosomes, spindles and kinetochores which are required for proper mitotic progression and maintaining genomic integrity and maintaining genomic integrity [10]. Since MYCN has role in neuroblastoma development, its overexpression supports the hypothesis that neural development pathways are implicated in the progression of the androgenindependent prostate cancer [10].

While the morphologic and immunohistochemical features of PSCC are often indistinguishable from SCC arising in other sites, recent studies have demonstrated a significant number of cases carrying ERG gene rearrangements leading to the TMPRSS2-ERG fusion, similar to conventional prostatic adenocarcinoma. TMPRSS2ERG fusion derived from ERG gene deletion and ERG gene translocations has been demonstrated by FISH analysis in $45 \%$ - $67 \%$ of prostatic SCC cases examined $[11,12]$, and has not been detected in cases of SCC arising from other sites such as bladder or lung. The presence of ERG protein in PSCC has also been detected by

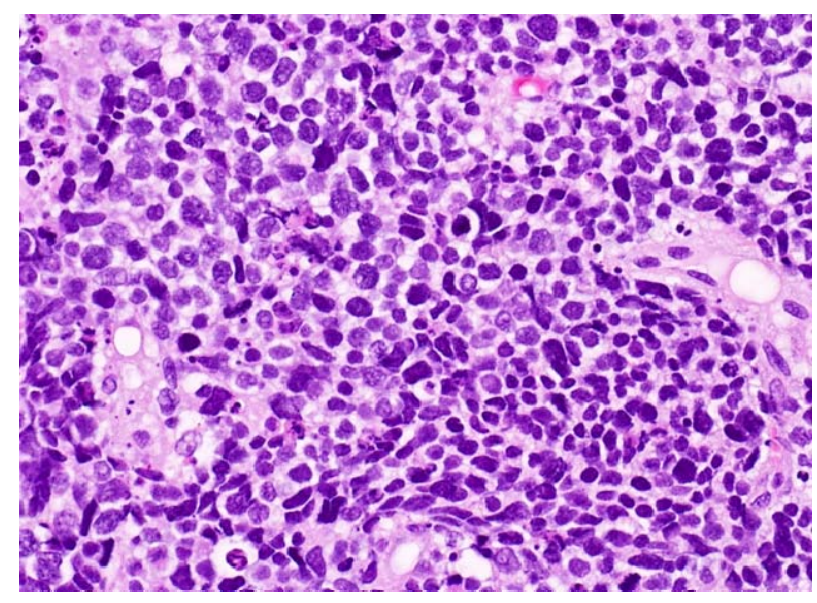

Figure 1. Characteristic appearance of small cell carcinoma, with minimal cytoplasm, apoptosis, and nuclear molding ( $\mathrm{H}$ \& E, 400× magnification).



Figure 2. Diffuse positive immunohistochemical staining for synaptophysin (200× magnification). 
immunohistochemistry (IHC), with one study showing ERG IHC to demonstrate $40 \%$ sensitivity and $92 \%$ specificity for ERG gene rearrangements as compared to FISH analysis [12]. These results suggest that ERG gene rearrangement analysis by FISH may be the most sensitive marker for prostate origin in metastatic PSCC, although there is insufficient data to predict whether TMPRSS2ERG gene fusion has prognostic impact.

\section{Treatment}

Small cell carcinoma being a rare disease, there is a paucity of randomized clinical trials with various treatment regimens. Various investigators have published their experiences as case series. There is a general consensus among clinicains that PSCC should be managed as small cell carcinoma of lung. Following is the description of clinical experience published in literature. Reports describing two or more patients were included in our report.

French group looked at 41 consecutive patients with diagnosis of PSCC based on predetermined features including, supra-normal serum neuron specific enolase and chromogranin A levels. None of these patients had biopsy confirmation for small cell features. Patients were treated with combination of docetaxel $75 \mathrm{mg} / \mathrm{m}^{2}$ and cisplatin $75 \mathrm{mg} / \mathrm{m}^{2}$ every 3 weeks for a maximum of $6 \mathrm{cy}-$ cles. The primary end point was neuroendocrine response defined as more than $50 \%$ decrease in level of tumor markers. It was seen in $33 \%$ of the patients. The median duration of response was 4 months (range 2 - 10 months). Prostate specific antigen response rate was $48 \%$. The objective response rate was $41 \%$ in patients with measurable disease [13]. At the end of observation all except 3 patients had died, including 37 of progressive prostatic cancer and 1 died of toxicity. Median survival from the onset of chemotherapy was 12 months (range 1 to 38) (Table 1-1.1).

Phase II trial of doxorubicin, etoposide and cisplatin conducted at MD Anderson in histo-pathologically proven pure or mixed small cell prostate cancer showed severe toxicity with the regimen. More than $8 \%$ died due to toxicity of the regimen. Dose modification was required for $45 \%$ of the patients. None of the patient achieved complete response. $61 \%$ patients had radiologic partial response out of which $46 \%$ were stable disease only. Median overall survival was only 10.5 months with median time to progression 5.8 months. All patients which had partial response also showed $50 \%$ reductions in tumor markers level including PSA, CEA, and LDH. [14] Some important observations made in this cohort by the investigators were that patient with mixed histology had a longer survival than patients with pure small cell histology. Also higher value of PSA predicted a lower risk disease and positive predictor of time to failure. A plausible explanation for this is that pretreatment PSA levels may reflect the percentage and the histologic maturity of the adenocarcinoma component coexisting with PSCC, which in turn may dictate the overall biologic behavior of the hybrid tumor [14] (Table 1-1.2).

Mitry et al. published their experience with cisplatin and etoposide in patients with metastatic tumors with neuroendocrine differentiation arising from other sites like foregut, mid gut and hindgut. They observed good response rates of $61 \%$ in patients with poorly differentiated tumors but dismal survival of $20 \%$ at 2 years [20].

Table 1. Different Chemotherapy regimens used for prostatic small cell carcinoma.

\begin{tabular}{|c|c|c|c|c|c|c|c|c|c|}
\hline Chemotherapy regimen & $\begin{array}{l}\text { Number } \\
\text { of patients }\end{array}$ & $\begin{array}{c}\text { Biopsy } \\
\text { confirmation }\end{array}$ & $\begin{array}{c}\text { Tumor } \\
\text { marker } \\
\text { elevation }\end{array}$ & $\begin{array}{l}\text { Tumor } \\
\text { marker } \\
\text { response }\end{array}$ & $\begin{array}{l}\text { Radiologic } \\
\text { response }\end{array}$ & $\begin{array}{l}\text { Median } \\
\text { survival }\end{array}$ & $\begin{array}{l}\text { Median } \\
\text { time to } \\
\text { progression }\end{array}$ & $\begin{array}{c}\text { Prior } \\
\text { treatment }\end{array}$ & Radiation \\
\hline Docetaxel + Cisplatin [13] & 41 & No & $\begin{array}{l}\text { Yes, NSE, } \\
\text { CGA }\end{array}$ & $33 \%$ & yes & $\begin{array}{c}12 \text { months after } \\
\text { chemotherapy } \\
\text { initiation }\end{array}$ & 4 & $\begin{array}{l}\text { Hormonal, } \\
\text { estramustine }\end{array}$ & None \\
\hline $\begin{array}{l}\text { Doxorubicin }+ \text { Cisplatin }+ \\
\text { Etoposide [14] }\end{array}$ & 38 & Yes & $\begin{array}{l}\text { Yes, LDH, } \\
\text { CEA, ALKP }\end{array}$ & Yes & $61 \% \mathrm{PR}$ & 10.5 & 5.8 & Hormonal & None \\
\hline Estramustine $[15,16]$ & 34 & No & CGA & Yes & Yes & 9 & 5.7 & Hormonal & None \\
\hline Cisplatin + Etoposide & 4 & & & & & & & & \\
\hline Carbo + Etoposide & 3 & & & & & & & & 6 out \\
\hline Cis + Adria + Vincristine & 1 & Yes & None & NA & NA & 9.5 & NA & NA & of 10 \\
\hline Cis + Adria + Tamoxifen & 1 & & & & & & & & \\
\hline Androgen Deprivation [17] & 1 & & & & & & & & \\
\hline Gem + Doce + Carbo & 2 & Yes & NSE & Yes & $100 \%$ & NA & NA & ADT in 1 patient & 1 \\
\hline $\begin{array}{l}\text { Cis }+ \text { Adria }+ \text { Etop } \\
\text { Cis }+ \text { Adria }+ \text { Vincristine }[18]\end{array}$ & $\begin{array}{l}1 \\
1\end{array}$ & Yes & CEA & Yes & NA & NA & NA & Ongoing & Yes \\
\hline
\end{tabular}


Ahel et al. used estramustine for androgen refractory prostate cancer with increased levels of chromogranin A levels. They found initial $65.3 \%$ response rate at 3 months with median time to progression 5.7 months and median survival of 9 months [15,21] (Table 1-1.3).

Asmis et al. presented their experience with PSCC with SCC arising in GU tract. Of 22 patients with SCC of GU tract, 10 were in prostate. 9 patients were advanced stage and 1 patient was limited stage. These patients received different combinations of chemotherapy-Cisplatin and etoposide [4], carboplatin and etoposide [3], Cisplatin, Adriamycin and vincristine [1]; cisplatin, Adriamycin and tamoxifen [1] and one patient receiving only hormonal therapy. Median survival for prostate cancer patients was 9.5 months. None of the patients developed symptomatic brain metastases [17] (Table 1-1.4).

Aoki et al. used gemcitabine, docetaxel and carboplatin in two patients with biopsy proven small cell carcinoma. Both patients had good radiographic and biochemical response. One patient died within 12 months with a recurrence. Second patient who had limited stage disease received chemotherapy followed by radiation boost to the pelvis but died of liver dysfunction from unrelated causes within three months of treatment completion [19] (Table 1-1.5).

Rubenstein et al. presented series of 7 cases where they used chemotherapy regimen using cisplatin, adriamycin and etoposide (one patient); cisplatin, adriamycin and vincristine as neo-adjuvant followed by cisplatin and etoposide after prostatectomy in the second patient. Paper doesn't clearly discuss what combination was used in other patients. They added RT to the pelvis in 3 of their patients. Survival of patients with mixed tumor histology was better than pure small cell prostate cancer. PSA was observed to be not a reliable marker of tumor progression in comparison to CEA, which mirrored the disease course very well [18] (Table 1-1.6).

\section{Recommendations}

Patients with castrate refractory prostate cancer should be investigated for small cell features if they have one or more of the following features: All patients of castrate refractory prostate cancer who are progressing rapidly with large volume of disease, predominant non bony disease, with or without asynchrony of their PSA level to the burden of disease, patients with prior histology of high Gleason grade disease.

Patients with suspicion of PSCC should get serum level drawn for tumor markers. Investigators have looked at various tumor markers in patient with PSCC to predict disease, response and relapse or progression. (Table 2) Neuron specific enolase was noted to be a good marker in small cell lung cancer as a marker of extent of disease and clinical response to chemotherapy [22]. If any of them
Table 2. Various Tumor markers used for follow up in patients with PSCC.

\begin{tabular}{l}
\hline Neuron Specific enolase [13,19] \\
\hline Chromogranin A [13,15] \\
Bombesin [14] \\
Calcitonin [14] \\
ACTH [14] \\
Carcino-embryonic Antigen [14,18] \\
Somatostatin [14] \\
LDH [14] \\
Alkaline phosphatase [13,14] \\
Pro- gastrin releasing peptide [19]
\end{tabular}

is elevated, it may help monitor the response to treatment. If possible core needle biopsy from a suitable site which is progressing rapidly on imaging should be performed. The pathologist should stain for CD56, synaptophysin, neuron specific enolase and chromogranin $\mathrm{A}$ in the tissue specimen.

The immune-histochemical demonstration of neuroendocrine differentiation is not a prerequisite for the diagnosis of small cell carcinoma [23]. Patients with neuroendocrine markers positive but not comprising of small cells should not be labeled as small cell carcinoma. Tissue may have mixed component of small cell and nonsmall cell architecture and they should be described as such.

If patients have high grade disease with neuroendocrine features but no small cell component then it is treated as regular prostate adenocarcinoma. Once the diagnosis is confirmed, as per national comprehensive cancer network recommendations PSCC is treated as small cell lung cancer [24]. In multiple randomized clinical chemotherapy trials for small cell lung cancer combination of cisplatin and etoposide trumped other alkylating agent containing regimens [25,26]. Meta-analysis of individual patient data treated with cisplatin and etoposide versus carboplatin and etoposide suggested no differences in efficacy between cisplatin and carboplatin in the first-line treatment of extensive stage SCLC, but there are differences in the toxicity profile [27]. In our opinion patients with metastatic small cell prostate cancer can be treated with either of the combination although in elderly men cisplatin is more difficult to administer with their base line poor renal function. Oral Topotecan is considered a good option as second line treatment for progressive disease [28]. 
If there is no evidence of metastasis outside pelvis then chemotherapy in combination of radiation therapy to the pelvis should be done [16]. Prophylactic cranial radiation is standard of care for limited stage SCC of the lung [29]. It is not clear if prophylactic cranial radiation has any role in this PSCC. In one of the case series patients with liver metastasis and high ACTH levels were noted to have higher risk of brain metastasis [14].

Authors recommend, if patients is diagnosed with prostate only disease, and patient is a surgical candidate then prostatectomy and lymph node dissection should be performed [30]. The rationale is that prostate may have adenocarcinoma component also. In larger series addition of chemotherapy to surgery at any point of disease course have shown to improve survival in patients with PSCC [30]. If surgical specimen shows high risk features adjuvant radiation to the field can be given [31]. Patient with bone metastasis should be given denosumab as this type of cancer is usually castrate resistant [32].

\section{New Directions}

Newer techniques developed to simplify molecular and genomic characterization for various tumors is helping us understand PSCC better. A recent genomic profiling study of prostate cancer patients had 7 cases of PSCC and all of them had overexpression of Aurora kinase A and MYC. Their xenograft models showed response to AURKA inhibitors [10]. In clinical study unselected metastatic castrate resistant prostate cancer patients who had progressed on previous chemotherapy were offered danusertib (PHA-739358). $13.6 \%$ of treated patients had stable disease for $\geq 6$ months [33]. It is possible in future if we enrich the population of patients by genomic profiling and offer them drug treatment based on this information we may observe better response rates.

\section{Conclusion}

In conclusion de novo PSCC is a very rare and aggressive phenotype of prostate cancer more commonly seen in younger males; evidence of focal neuroendocrine differentiation is present in patients with prostate adenocarcinoma at diagnoses and increases with disease progresssion [34]. Clinician should attempt to diagnose it early and treat aggressively with multimodality approach to improve survival.

\section{REFERENCES}

[1] D. M. Marcus, M. Goodman, A. B. Jani, A. O. Osunkoya and P. J. Rossi "A Comprehensive Review of Incidence and Survival in Patients with Rare Histological Variants of Prostate Cancer in the United States from 1973 to 2008," Prostate Cancer Prostatic Diseases, Vol. 15, No. 3, 2012, pp. 283-288. doi:10.1038/pcan.2012.4
[2] W. Wang and J. I. Epstein, "Small Cell Carcinoma of the Prostate: A Morphologic and Immunohistochemical Study of 95 Cases," American Journal of Surgical Pathology, Vol. 32, No. 1, 2008, pp. 65-71. doi:10.1097/PAS.0b013e318058a96b

[3] A. Aparicio, V. Tzelepi, J. C. Araujo, C. C. Guo, S. Liang, P. Troncoso, et al., "Neuroendocrine Prostate Cancer Xenografts with Large-Cell and Small-Cell Features Derived from a Single Patient's Tumor: Morphological, Immunohistochemical, and Gene Expression Profiles," The Prostate, Vol. 71, No. 8, 2011, pp. 846-856. doi:10.1002/pros.21301

[4] A. G. Aprikian, C. Cordon-Cardo, W. R. Fair, Z. F. Zhang, M. Bazinet, S. M. Hamdy, et al., "Neuroendocrine Differentiation in Metastatic Prostatic Adenocarcinoma," The Journal of Urology, Vol. 151, No. 4, 1994, pp. 914-919.

[5] N. P. Caraway, C. V. Fanning, H. J. Shin and R. J. Amato, "Metastatic Small-Cell Carcinoma of the Prostate Diagnosed by Fine-Needle Aspiration Biopsy," Diagnostic Cytopathology, Vol. 19, No. 1, 1998, pp. 12-16. doi:10.1002/(SICI)1097-0339(199807)19:1<12::AID-DC 4>3.0.CO;2-Q

[6] J. L. Yao, R. Madeb, P. Bourne, J. Lei, X. Yang, S. Tickoo, et al., "Small Cell Carcinoma of the Prostate: An Immunohistochemical Study," American Journal of Surgical Pathology, Vol. 30, No. 6, 2006, pp. 705-712. doi:10.1097/00000478-200606000-00005

[7] H. Chen, Y. Sun, C. Wu, C. E. Magyar, X. Li, L. Cheng, et al., "Pathogenesis of Prostatic Small Cell Carcinoma Involves the Inactivation of the P53 Pathway," Endocrine-Related Cancer, Vol. 19, No. 3, 2012, pp. 321-331. doi:10.1530/ERC-11-0368

[8] T. Terada, "Small Cell Neuroendocrine Carcinoma of the Prostate: Incidence and a Report of Four Cases with an Examination of KIT and PDGFRA," The Prostate, Vol. 72, No. 10, 2012, pp. 1150-1156. doi:10.1002/pros.22464

[9] N. Clegg, C. Ferguson, L. D. True, H. Arnold, A. Moorman, J. E. Quinn, et al., "Molecular Characterization of Prostatic Small-Cell Neuroendocrine Carcinoma," The Prostate, Vol. 55, No. 1, 2003, pp. 55-64. doi:10.1002/pros. 10217

[10] H. Beltran, D. S. Rickman, K. Park, S. S. Chae, A. Sboner, T. Y. MacDonald, et al., "Molecular Characterization of Neuroendocrine Prostate Cancer and Identification of New Drug Targets," Cancer Discovery, Vol. 1, No. 6, 2011, pp. 487-495. doi:10.1158/2159-8290.CD-11-0130

[11] C. C. Guo, J. Y. Dancer, Y. Wang, A. Aparicio, N. M. Navone, P. Troncoso, et al., "TMPRSS2-ERG Gene Fusion in Small Cell Carcinoma of the Prostate," Human Pathology, Vol. 42, No. 1, 2011, pp. 11-17. doi:10.1016/j.humpath.2010.05.026

[12] T. L. Lotan, N. S. Gupta, W. Wang, A. Toubaji, M. C. Haffner, A. Chaux, et al., "ERG Gene Rearrangements Are Common in Prostatic Small Cell Carcinomas," Modern Pathology, Vol. 24, No. 6, 2011, pp. 820-828. doi:10.1038/modpathol.2011.7

[13] S. Culine, M. El Demery, P. J. Lamy, F. Iborra, C. Avances and F. Pinguet, "Docetaxel and Cisplatin in Patients with Metastatic Androgen Independent Prostate 
Cancer and Circulating Neuroendocrine Markers," The Journal of Urology, Vol. 178, No. 3, 2007, pp. 844-848.

[14] C. N. Papandreou, D. D. Daliani, P. F. Thall, S. M. Tu, X. Wang, A. Reyes, et al., "Results of a Phase II Study with Doxorubicin, Etoposide, and Cisplatin in Patients with Fully Characterized Small-Cell Carcinoma of the Prostate," Journal of Clinical Oncology, Vol. 20, No. 14, 2002, pp. 3072-3080. doi:10.1200/JCO.2002.12.065

[15] M. Z. Ahel, K. Kovacic, I. Kraljic and M. Tarle, "Oral Estramustine Therapy in Serum Chromogranin A-Positive Stage D3 Prostate Cancer Patients," Anticancer Research, Vol. 21, No. 2B, 2001, pp. 1475-1479.

[16] D. B. Fried, D. E. Morris, C. Poole, J. G. Rosenman, J. S. Halle, F. C. Detterbeck, et al., "Systematic Review Evaluating the Timing of Thoracic Radiation Therapy in Combined Modality Therapy for Limited-Stage Small-Cell Lung Cancer," Journal of Clinical Oncology, Vol. 22, No. 23, 2004, pp. 4837-4845. doi:10.1200/JCO.2004.01.178

[17] T. R. Asmis, M. N. Reaume, S. Dahrouge and S. Malone, "Genitourinary Small Cell Carcinoma: A Retrospective Review of Treatment and Survival Patterns at the Ottawa Hospital Regional Cancer Center," BJU International, Vol. 97, No. 4, 2006, pp. 711-715. doi:10.1111/j.1464-410X.2006.06041.x

[18] J. H. Rubenstein, M. J. Katin, M. M. Mangano, J. Dauphin, S. A. Salenius, D. E. Dosoretz, et al., "Small Cell Anaplastic Carcinoma of the Prostate: Seven New Cases, Review of the Literature, and Discussion of a Therapeutic Strategy," American Journal of Clinical Oncology, Vol. 20, No. 4, 1997, pp. 376-380. doi:10.1097/00000421-199708000-00011

[19] H. Aoki, S. Ishidoya, A. Ito, M. Endoh, T. Shimazui and Y. Arai, "Experience of the Treatment with Gemcitabine, Docetaxel, and Carboplatin (GDC) Chemotherapy for Patients with Small-Cell Carcinoma of the Prostate," International Journal of Urology, Vol. 13, No. 9, 2006, pp. 1254-1258. doi:10.1111/j.1442-2042.2006.01514.x

[20] E. Mitry, E. Baudin, M. Ducreux, J. C. Sabourin, P. Rufie, T. Aparicio, et al., "Treatment of Poorly Differentiated Neuroendocrine Tumours with Etoposide and Cisplatin," British Journal of Cancer, Vol. 81, No. 8, 1999, pp. 13511355. doi:10.1038/sj.bjc.6690325

[21] M. Z. Ahel, K. Kovacic, I. Kraljic and M. Tarle, "Oral Estramustine Therapy in Serum Chromogranin A-Positive Stage D3 Prostate Cancer Patients," Anticancer Research, Vol. 21, No. 2B, 2001, pp. 1475-1479.

[22] D. N. Carney, P. J. Marangos, D. C. Ihde, P. A. Bunn Jr., M. H. Cohen, J. D. Minna, et al., "Serum Neuron-Specific Enolase: A Marker for Disease Extent and Response to Therapy of Small-Cell Lung Cancer," The Lancet, Vol. 319, No. 8272, 1982, pp. 583-585. doi:10.1016/S0140-6736(82)91748-2

[23] K. Junker, T. Wiethege and K. M. Muller, "Pathology of Small-Cell Lung Cancer," Journal of Cancer Research and Clinical Oncology, Vol. 126, No. 7, 2000, pp. 361368. doi:10.1007/PL00008483

[24] National Comprehensive Cancer Network, "NCCN Clinical Practice Guidelines," 2013. http://www.nccn.org/professionals/physician_gls/pdf/pros tate.pdf
[25] S. Sundstrom, R. M. Bremnes, S. Kaasa, U. Aasebo, R. Hatlevoll, R. Dahle, et al., "Cisplatin and Etoposide Regimen is Superior to Cyclophosphamide, Epirubicin, and Vincristine Regimen in Small-Cell Lung Cancer: Results from a Randomized Phase III Trial with 5 Years' Follow-Up," Journal of Clinical Oncology, Vol. 20, No. 24, 2002, pp. 4665-4672. doi:10.1200/JCO.2002.12.111

[26] B. J. Roth, D. H. Johnson, L. H. Einhorn, L. P. Schacter, N. C. Cherng, H. J. Cohen, et al., "Randomized Study of Cyclophosphamide, Doxorubicin, and Vincristine versus Etoposide and Cisplatin versus Alternation of These Two Regimens in Extensive Small-Cell Lung Cancer: A Phase III Trial of the Southeastern Cancer Study Group," Journal of Clinical Oncology, Vol. 10, No. 2, 1992, pp. 282291.

[27] A. Rossi, M. Di Maio, P. Chiodini, R. M. Rudd, H. Okamoto, D. V. Skarlos, et al., "Carboplatin- or CisplatinBased Chemotherapy in First-Line Treatment of SmallCell Lung Cancer: The COCIS Meta-Analysis of Individual Patient Data," Journal of Clinical Oncology, Vol. 30, No. 14, 2012, pp. 1692-1698. doi:10.1200/JCO.2011.40.4905

[28] M. E. O’Brien, T. E. Ciuleanu, H. Tsekov, Y. Shparyk, B. Cucevia, G. Juhasz, et al., "Phase III Trial Comparing Supportive Care Alone with Supportive Care with Oral Topotecan in Patients with Relapsed Small-Cell Lung Cancer," Journal of Clinical Oncology, Vol. 24, No. 34, 2006, pp. 5441-5447. doi:10.1200/JCO.2006.06.5821

[29] G. R. Simon and H. Wagner, "American College of Chest Physicians. Small Cell Lung Cancer," Chest, Vol. 123, No. 1, 2003, pp. 259S-271S. doi:10.1378/chest.123.1 suppl.259S

[30] J. R. Mackey, H. J. Au, J. Hugh and P. Venner, "Genitourinary Small Cell Carcinoma: Determination of Clinical and Therapeutic Factors Associated with Survival," The Journal of Urology, Vol. 159, No. 5, 1998, pp. 1624-1629. doi:10.1097/00005392-199805000-00058

[31] M. Bolla, H. van Poppel, B. Tombal, K. Vekemans, L. Da Pozzo, T. M. de Reijke, et al., "Postoperative Radiotherapy after Radical Prostatectomy for High-Risk Prostate Cancer: Long-Term Results of a Randomised Controlled Trial (EORTC Trial 22911)," The Lancet, Vol. 380, No. 9858, 2012, pp. 2018-2027. doi:10.1016/S0140-6736(12)61253-7

[32] K. Fizazi, M. Carducci, M. Smith, R. Damiao, J. Brown, L. Karsh, et al., "Denosumab versus Zoledronic Acid for Treatment of Bone Metastases in Men with CastrationResistant Prostate Cancer: A Randomised, Double-Blind Study," The Lancet, Vol. 377, No. 9768, 2011, pp. 813822. doi:10.1016/S0140-6736(10)62344-6

[33] H. J. Meulenbeld, J. P. Bleuse, E. M. Vinci, E. Raymond, G. Vitali, A. Santoro, et al., "Randomized Phase II Study of Danusertib in Patients with Metastatic Castration-Resistant Prostate Cancer after Docetaxel Failure," BJU International, Vol. 111, No. 1, 2013, pp. 44-52.

[34] A. Berruti, A. Mosca, F. Porpiglia, E. Bollito, M. Tucci, F. Vana, et al., "Chromogranin A Expression in Patients with Hormone Naive Prostate Cancer Predicts the Development of Hormone Refractory Disease," The Journal of Urology, Vol. 178, No. 3, 2007, pp. 838-843, 1129. 


\section{Abbreviation List}

PSCC: Prostatic small cell carcinoma

SEER: Surveillance, Epidemiology and End Results

PSA: Prostate Specific Antigen

SCC: Small Cell Carcinoma

CD56: Cluster of differentiation marker 56

PDGFR: Platelet Derived Growth Factor Receptor

AMACR: Alpha Methylacyl CoA Racemase

P53: Protein 53

PCR: Polymerase Chain Reaction

MYCN: Neuroblastoma derived myelocytomatosis oncogene
TMPRSS2: Transmembrane protease serine 2 ERG: Ets related gene

AURKA: Aurora Kinase A

FISH: Fluorescence in-situ hybridization

IHC: Immunohistochemistry

CEA: Carcinoembryonic antigen

LDH: Lactate dehydrogenase

GU: Genitourinary

RT: Radiation Therapy

SCLC: Small Cell Lung Cancer

ACTH: Adrenocorticotropic hormone 